\title{
Paraphrases and summaries: A means of clarification or a vehicle for articulating a preferred version of student accounts?
}

\author{
Mike Brown
}

\begin{abstract}
The use of group discussions as a means to facilitate learning from experiences is well documented in adventure education literature. Priest and Naismith (1993) assert that the use of the circular discussion method, where the leader poses questions to the participants, is the most common form of facilitation in adventure education. This paper draws on transcripts of facilitation sessions to argue that the widely advocated practice of leader summaries or paraphrases of student responses in these sessions functions as a potential mechanism to control and sponsor particular knowledge(s). Using transcripts from recorded facilitation sessions the analysis focuses on how the leader paraphrases the students' responses and how these paraphrases or 'formulations' function to modify or exclude particular aspects of the students' responses. I assert that paraphrasing is not simply a neutral activity that merely functions to clarify a student response, it is a subtle means by which the leader of the session can, often inadvertently or unknowingly, alter the student's reply with the consequence of favouring particular knowledge(s). Revealing the subtle work that leader paraphrases perform is of importance for educators who claim to provide genuine opportunities for students to learn from their experience.
\end{abstract}

\section{Introduction}

How knowledge is articulated and whose knowledge is privileged are issues at the very core of adventure education theory (Brown, 2002a, 2002b). If we are serious about the centrality of the learner's experience as the basis of valid knowledge then a critical appreciation of the role paraphrases play in verbal facilitation sessions is important. In explicating the 'unseen' and unrealised consequences of our actions we may have reason to modify current theory and practice. This paper begins with a brief exposition of some commonly available explanations of facilitation, the role of the leader in adventure education facilitation sessions and how paraphrasing/summarising students' contributions is considered to be a function that the leader can perform to assist students in their learning. In the analysis section two transcripts are analyzed in detail to show how the leader's use of paraphrases alters the students' original response. This is followed by a discussion on the implications of these findings for practice. Readers who wish to pursue this analytic approach further may which to read the follow succinct articles (Baker, 1997; Heap, 1997; Maynard \& Clayman, 1991).

\section{Facilitation/processing of experience}

Facilitation of experience with adventure education is well documented and is variously described as debriefing, processing and reflecting (Brackenreg, Luckner, \& Pinch, 1994; Dickson, 1996; Luckner \& Nadler, 1997; Priest \& Gass, 1997; Quinsland \& Van Ginkel, 1984). In this paper the term facilitation is used to describe verbal discussions conducted with students prior to, or at the conclusion of an activity, with the ostensible aim of assisting them to learn from an experience.

Facilitation of an experience is considered desirable within the experiential framework as it assists the student to sort and order information in a meaningful way and therefore aid in learning that is lasting and transferable (Boud, Keogh, \& Walker, 1985; Joplin, 1995; Luckner \& Nadler, 1997; Priest \& Gass, 1997). According to Priest, Gass and Gillis (2000 p. 19) facilitation is the 
process of conducting a discussion "as a means to reflect on, learn from, and change as a result of experiences". The 'desirability' of the public articulation of one's experience is reinforced by Joplin (1995 p. 19) who states that, "the public nature of debrief also ensures that the learner's conclusions are verified and mirrored against a greater body of perception than his [sic] alone".

The role of discussion is also emphasized by Priest et al. (2000 p. 19) who state that, experience alone does not lead to learning or change unless it is accompanied by some form of reflection. Clients frequently become caught up in the power of their learning experiences and often miss the meaning of its message. Facilitated discussion helps the clients uncover and accelerate learning and supports them through their change processes.

\section{The role of the leader in conducting verbal facilitation sessions}

The literature reveals many possible descriptors for the person responsible for group management in adventure education settings, including; instructor, teacher, facilitator and leader. For consistency I have used the term 'leader' but have retained the various descriptors as used by others in direct quotations.

In emphasising the importance of direct experience and reflection for learning, adventure education is often purported to be an example of student-centred learning. Within the literature on facilitation the leader is often positioned in an idealised role where s/he is seen as a neutral or background figure to the 'real' action, which is the students reflecting on and speaking of their experiences. Chapman (1995) maintains that the leader's role is to give just enough assistance for students to be successful, 'but no more'. He argues that if the approach is truly student-centred, students may not be aware the leader had a role at all. Sugarman, Doherty, Garvey and Gass (2000) consider that the role of the leader is to "set up an environment where learning through reflection can take place and all participants are able to understand the meaning of the experience for them" (p.9). Others
(Chapman, 1995; Joplin, 1995) maintain that the role for the leader is to help students make connections between an activity and other life situations so that actions do not drift along unquestioned or unintegrated. Chapman (1995) suggests that the teaching process in adventure education is similar to setting a trap

For me, the art of teaching has much to do with the ability to develop many disparate pieces of experience- to bring them into place while resisting the temptation to make the points for students. The teacher must understand the point of the activities in these terms in order to set a good trap, and must intentionally teach toward that climatic moment (p.238)

Somewhat ambiguously, Chapman goes on to explain that leaders in adventure education are like coaches who "are largely removed from their roles as interpreters of reality, purveyors of truth, mediators between students and the world" (p.239). Students are therefore apparently free to draw valid and meaningful conclusions from their own experiences. It is also claimed that the elicitation of student generated responses coupled with appropriate processing of the activity allows adventure educators to move "beyond teacher-student rhetoric to enhance deep learning within students" (Spegel, 1996 p. 30).

In much of the literature (Brackenreg et al., 1994; Gass, 1990; Knapp, 1990; Luckner \& Nadler, 1997; Priest \& Gass, 1997; Quinsland \& Van Ginkel, 1984) the leader is positioned as the person who is able to assist the program participants to discover their own meaning of an experience by providing an appropriate framework for discussions. The leader is portrayed as a benevolent guide who is not actively involved in directing and orchestrating the student reflection and learning process.

While numerous commentators have remarked on the role of verbal processing and the leader's role in guiding student 'self discovery', some observers (Bell, 1993; Boud, 1997; Bowles, 1996; Estes \& Tomb, 1995) have questioned how verbal facilitation is enacted and how it positions the participants in these sessions. Boud (1997) claims that present 
conceptualisations of facilitation and the role of the facilitator are often based in notions of group relations training and are not sufficiently critically aware of the need to acknowledge diversity in the promotion of learning from experience. They are, he fears, too rooted in the "older humanistic notion of facilitation, or worse direct instruction" (p. 1). Both Bell (1993) and Bowles' (1996) express concerns regarding the position adopted in some texts that imply that participants are not "fit to give justice to their own potential" (Bowles, 1996 p. 11) and therefore they need prompting by the leader to achieve certain outcomes. Bell (1993) goes on to argue that the imposition of a homogeneous theory of experience as advocated in much adventure education literature is problematic. She questions the opportunities that are made available for differences in experiences, other than the dominant discourses, to be legitimated.

Estes and Tomb (1995) state that the increasing emphasis on leader-directed processing in adventure education may be devaluing both the learning experience and the promotion of self-reliance among participants. They suggest that over processing can be problematic as it is the leader rather than the student who decides what was learned and its relative value (Estes \& Tomb, 1995). While not doubting the importance of facilitating an experience to assist in the transfer of learning, they question how this should occur

When the teacher, and not the student, is directing the process of deciding what the experience means to the students a problem arises. The problem is that when the teacher is directive during discussion, he or she has taken on the responsibility for deciding what was to be learned. This denies the value of self-reliance because students are not making choices about how they should organize meaning from their experiences (p. 40).

Similarly Proudman (1995) suggests that the leader may take too active a role is achieving particular outcomes

Responsibility cannot be nurtured in the learner if the teacher creates or expects the learner to learn for the teacher's (or someone else's) sake.
As an example, I have experienced teachers excitedly telling students exactly where to place their hands and feet while on a climbing wall, under the guise of helping the student succeed and "get to the top". But this approach raises several critical questions: whose experience is it? Whose definition of success is being used? What is the goal of the activity for the student? How interested is the teacher in guaranteeing a certain student outcome? Too often, teachers allow their unconscious conditioning to interfere with opportunities for student selfdiscovery (p. 243).

Regardless of these concerns it is widely accepted that the role of the leader is to enhance the reflective process and provide catalysts for learning through the establishment of a context in which participants can extract meaning from their experiences (Sugarman et al., 2000). These catalysts include the facilitator's use of specific techniques to help "individuals sort information into recognizable patterns and make connections between past experiences and current learning" (Sugarman et al., 2000 p. 7). It is the use of one such 'specific technique', namely leader paraphrases of student responses, to which my attention will now turn.

\section{Paraphrases/summaries or Formulations}

I have used the term 'formulations', drawn from ethnomethodology, to refer to the act of paraphrasing or summarising what another participant in the conversation has said. Ethnomethodological studies focus on the common-sense and routine knowledge(s) used by participants as they interact in social activities. In examining how people use language in the ongoing process of social interaction, ethnomethodologists focus on understanding the actions that result from talk (Baker, 1997).

The use of leader formulations, although not necessarily referred to in this terminology, is widely advocated in adventure education literature as a means of assisting students to make 'connections', to clarify, and to understand what was 'really' meant by a previous speaker. The following passages 
provide an overview of the position advocated by several writers with regard to the use of paraphrases/summaries by the leader in group discussions. Priest and Gass (1997 p. 251) recommend that paraphrases be used

to confirm concepts and to determine if the receiver correctly understood the meaning of the sender's ideas. Paraphrasing is more than the mere repetition of a statement word for word: it is a more thorough reiterating of statements with different words.

Luckner and Nadler (1997) also mention the role of paraphrasing as a way of filtering or clarifying what another person has spoken about.

In paraphrasing, we restate in our own words what we think another person has just said. This provides the sender with an opportunity to agree or further refine the message. Paraphrasing focuses on relatively small units of information that were discussed by the other individual, and it involves little or no inference. By accurately restating the main points of a person's statement, we demonstrate that we have been attending to and accurately understanding what the person has been relating thereby conveying an interest in the message as well as in the person. When paraphrasing, we want to try to (a) be concise-including only the essential ideas, concepts, themes of the speaker's message, and (b) focus on the content of the speaker's message- deal with the facts or ideas rather than the emotions the sender is expressing ( $p$. 84).

Luckner and Nadler (1997) also refer to summarising as a way to 'gather up' the contributions of a number of participants and to provide the group with the gist of what was said so that confirmations or revisions can be made.

Summarizing consists of one or more statements that restate, in succinct form, several preceding statements made by the individuals involved in the interaction. By feeding back to speakers the gist of their message, we validate the communication, which often inspires further communication. It is also a means of ensuring that all individuals involved understand what has been said. Specifically, it gives all individuals a chance to hear the key points and to agree what was said or to disagree and revise the content of the interaction and make some clarifications regarding key ideas or events ( p. 86).

The authors of these practical guides to facilitation acknowledge the way that paraphrases and summaries (or formulations) can act as a way to 'fix' meaning. This 'saying-of-what-we-aretalking-about' or formulating has been extensively documented in ethnomethodological literature as a way to 'fix' meaning in conversation (Garfinkel \& Sacks, 1970; Heritage \& Watson, 1979; Heyman, 1986). However, as I shall discuss, whose meaning is being fixed and publicly articulated? What are the consequences for the knowledge that is being produced and valued? As will be highlighted, it is through the act of formulating the student's contribution that the leader is able to exercise a powerful tool to state the 'real learning' that has occurred.

\section{Formulations as a feature of conversation}

As a conventional form of serially organised conversational devices formulations refer to the manner in which a participant may

treat some part of the conversation as an occasion to describe that conversation, to explain it, or characterize it, or explicate, or translate, or summarize, or furnish the gist of it....That is to say, a member may use some part of the conversation as an occasion to formulate the conversation.... (Garfinkel \& Sacks, 1970 p. 350).

An understanding of the practical actions that can be accomplished through the employment of formulations as a conversational device is important, as formulations have real and important consequences for the sequential development of talk (Heyman, 1986). The formulating work of participants in a conversation becomes a topic for 
ethnomethodological analysis as formulations are a device that members use in an effort to achieve a sense of orderliness and meaning in talk (Garfinkel \& Sacks, 1970; Heritage \& Watson, 1979; Heyman, 1986).

In examining the use of formulations in facilitation sessions I am interested in how the leader re-articulates the student reply into an 'acceptable' form which conveys the 'real' meaning. It is through the leader's formulations, and the students' acceptance of such formulations, that the participants can be seen to be attending to the ongoing management of conversational and social order.

\section{Formulations as a way to 'fix' meaning}

As the recipient of the student's reply the leader may choose to take responsibility for formulating the gist or sense of the utterance 'thus far' (Garfinkel \& Sacks, 1970; Heritage \& Watson, 1979; 1980; Smith, 1996). The leader's clarification of the sense of the student's utterance acts as a means to demonstrate what was 'really meant' to all the students in the group. Heritage and Watson (1979) assert that, "the primary business of formulations is to demonstrate understanding and, presumptively, to have that understanding attended to and ... endorsed" (p.138). Therefore the practical use of formulations is to establish a collaborative and jointly accepted statement of what is being talked about. Formulations cannot provide a 'once-and-for-all-solution' to the meaning of an utterance (Heritage \& Watson, 1979), what they can do is provide the participants with a reasonable and practical understanding of what has been spoken about (Smith, 1996). The articulation of an unequivocal display of understanding can be achieved through the use of a formulation that transforms or paraphrases a prior utterance. A formulation may involve the preservation of relevant features of a prior utterance, the deletion of irrelevant portions, and the emphasizing of significant points. In so doing the prior utterance is recast in a manner that enables the formulator (in this case the leader) to settle on one of many possible interpretations of what has been said (Heritage \& Watson, 1979).

\section{In-built preference for the confirmation of formulations.}

To understand the work of formulations in conversational organisation it is necessary to examine how they are introduced into talk and how participants display sequentially appropriate responses to formulations. Sequential appropriateness refers to the way that one utterance places a constraint on the production of the next utterance (e.g. on receipt of a greeting one is expected to produce an appropriate response; a reply. This is referred to as the greeting-reply adjacency pair). In that formulations act as a participant's 'publicly aired' understanding of a preceding section of talk they are deeply implicative for subsequent talk. Heritage and Watson (1979) point out that it is this sequential nature of the adjacency pair structure that requires that there be a 'formulation-decision' pair. While the decision part of this adjacency pair can either take the form of a confirmation or disconfirmation of the formulation, it has been argued (Heritage \& Watson, 1979) that there is an overwhelming preference for confirmations of the formulation as presented. A notable exception to this preference occurs when a formulation contains an accusation, with reference to the speaker, in which case, "the sequential appropriateness of a denial as a second pair part to an accusation overrides the preference for an acceptance as a second pair part to the formulation in which the accusation is embedded" (Heritage \& Watson, 1979, p. 157).

Heritage and Watson (1979) suggest that disconfirmations of formulations, may jeopardise the sense of order and accountability of 'the talk thus far' for members' collaborative constructions. They suggest that to fault a formulation directly may serve to terminate the present topic of talk. Additionally, to fault a formulation may constitute a criticism of the formulator's attention to what has been talked about. The implication is that a disconfirmation may question the integrity of previous utterances by the formulator. It is therefore reasonable to suggest that in facilitation settings a direct faulting of the leader's formulation could jeopardise or disrupt the ongoing collaborative production of the facilitation session and the social order. 
The fact that formulations are deeply implicative for the development of subsequent talk (Heritage \& Watson, 1979) has important ramifications for what can be said in facilitation sessions. Formulations constrain the form of the next turn at talk to that of a decision, a decision which will almost always agree with the formulation as presented. A leader's formulation acts as an indicator of the reasonableness and therefore 'commonly heard' understanding of the student's reply. Having arrived at a 'common understanding' the leader is now permitted to terminate the present student's turn at talk and move to the next student's contribution to the discussion.

Through the use of a formulation the leader can work with the student's response to produce an appropriate version of what counts as knowledge in this setting. It is through the use of leader-supplied formulations that 'officially sanctioned' understandings can be displayed and any discrepancies in meaning remedied. In formulating a student's reply, or by producing the final turn at the end of a round of contributions, the leader is able to formulate a response or a collective gist in a way that establishes a "rounded and concluded signature" (Heritage \& Watson, 1979 p. 155). A detailed examination of the use of formulations by the leader is therefore fundamental to an understanding of how valued knowledge is created and maintained in these settings.

\section{Transcript presentation and analysis}

By way of illustrating the arguments, two short extracts are presented from a larger corpus of data (Brown 2002b). The students were year nine boys from an Australian independent (private) school. Each group consisted of approximately 15 students and two leaders. The students were participating in a four day program as part of the school's standard curriculum. The program consisted of two days of river journey and two days of residential activities. Most, if not all of these students had previously participated in the school's sequential outdoor education program. For many students this was their third outdoor education experience at the school. The leaders were specialist outdoor education teachers employed by the school. Both leaders were males. All participants agreed to participate in the study and were aware that the discussion was being discretely recorded. The researcher acted as a participant observer but did not contribute to the discussions. Three weeks of data, each week featuring a new group of students with the same leaders, was collected from facilitation sessions and was transcribed by the researcher. The two transcripts presented are concerned with instances of leader formulations of a student reply where the formulation is met with a student-issued confirmation (as part of the formulationdecision adjacency pair). The student confirmation is followed by the leader's acceptance which draws the present student's turn at talk to an end and invites the next speaker to begin.

This conversation can be expressed in the following way:

$S=$ student; $L=$ leader

(S) Reply - (L) Formulation - (S)

Decision - (L) Acceptance

Transcription symbols:

(.) pause of $1 / 10 \mathrm{sec}$ ( 0.5$)$ half a second pause

Underlined: word which is stressed

[ ] overlapped word(s)

$=$ an utterance that is the continuation

of a previous turn at talk

\section{$\underline{\text { Transcript } 1}$}

The topic on which the students are asked to contribute is as follows;

Source: A

$1 \quad \mathrm{~L} \quad$... we want each person (0.3) to say (0.8) one (0.7) short (0.7) clear (0.7) statement ... I want it to be something that's going to be essential (0.8) for (0.4) this group for us (0.8) to have a successful day today (1.5) what do we need (.)... and some of it might be equipment but you have to say what (0.7) thing that the equipment is important for $(0.9)$ each person needs to say $(0.9)$ something different 
(1.7) a'right $(0.6)$ and it has to be something to do with our group (0.2) ... you need to say why that's important for the group (1.5) ... you might think of some other things that are not to do with equipment that are just to do with (0.4) how people work together or how people relate

\section{$\underline{\text { Transcript }}$}

Source: A

68 S1 wear sunscreen so you don't (0.5) get burnt like me (1.2)

$69 \mathrm{~L} \quad$ okay (0.5) so you've learned from the experience that you've had this week (0.5)

70 s1 yep

71 L excellent (0.6) 


\section{Analysis}

In his first turn at talk (turn 68) the student offers up a response 'wear sunscreen so you don't (0.5) get burnt like me (1.2)'. In his answer the student provides the leader with a resource from the 'learning from experience' discourse, which is subsequently taken up and expanded on by the leader. In replying the leader acknowledges the response with 'okay' followed by a pause and a formulation of the student response; 'so you've learned from the experience that you've had this week'. In the leader's formulation there is no mention of any of the specific items (sunscreen or getting burnt) raised by the student in his reply. The leader takes the student's response, (wearing sunscreen) which is a specific example of something that will help the group have a successful day today, and formulates it in a manner that emphasizes the value of learning that has occurred this week. This formulation picks up on the discourse of 'transfer' that is central to the experiential learning model (Kolb, 1984). While the formulation may 'capture' the fact that $\mathrm{S} 1$ has learned from the experience it does not specifically address the topic; something essential for the group to have a successful day today. The formulation highlights the leader's emphasis on learning from experience. In turn 70 the student agrees with the leader's formulation of his initial response with his agreement 'yep'. The leader uses the high-grade assessment 'excellent' to conclude S1's turn at talk. It has been argued (Antaki, HoutkoopStennstra, \& Rapley, 2000) that the use of a high-grade assessments, such as 'great', 'excellent' do not necessarily relate to the quality of the content of the student's answer, rather they function as a marker of the completion of a section of talk. The 'excellent' acknowledges the receipt of an exchange that has met the criteria for acceptance and allows the leader to continue with an "institutionally predictable routine" (Antaki et al., 2000, p. 243). By not issuing an immediate acceptance and through formulating the student's initial response into a more appropriate version the leader has used the student's reply as a resource with which to articulate his understanding of a contextually appropriate response. That the student agrees with the leader's formulation is to be expected as it is the preferred option within the formulationdecision adjacency pair. In addition to indicating the completion of the student's turn as part of the ongoing procedural requirement, 'excellent' (turn 71) could be understood as an evaluation of the student's agreement with the leader's formulation. With 'excellent', the leader is accepting and evaluating the correctness of the student's agreement with his (the leader's) formulation. The 'excellent' could possibly be heard as a confirmation on the part of the leader that the student has agreed to his formulation that he has 'learned from the experience'.

The specific issues raised in the student's initial reply, the need to avoid getting burnt, or the need to apply sunscreen are ignored by the leader. As 'something that's going to be essential (0.8) for (0.4) this group for us $(0.8)$ to have a successful day today' sunscreen does not feature as a worthy 'mentionable' in this context; it is the more abstract 'learning from experience' that is valued knowledge. The leader has provided a formulation of the 'unexplicated gist' (Heritage \& Watson, 1979) of the student's reply and in doing so has proffered his understanding of what the student 'really' meant in this situation. He has moved beyond the requirements of the original topic, 'things that will be useful for the group today', and expanded on the resource of 'experience' provided by the student. In doing so he is drawing on 'leader knowledge' to instruct the students as to the value of the experience for them this week. In this transcript the student has indicated that he has learned from the experience, which is after all, one of the desired outcomes of adventure education programs.

In transcript two the student is responding to the following topic outlined by the leader 
Source: B

$1 \mathrm{~L}$

so that we ah (.) so that we all understand what our responsibilities are why we're here (.) what l'd like each of you to do is tell me (1.0) um why (1.5) our school (1.2) has (0.5) year nine camp (1.0) why are you here on year nine camp (.5) from the school's perspective not from your personal perspective we'll start we're going to go round the circle so we'll start with $(0.5)$

\section{$\underline{\text { Transcript }}$}

Source: B

16 S1

17 L

$18 \quad \mathrm{~S} 1$

19 L

20 S2

I'm Len um (1.5) so (.5) teach us about the bush and have fun stuff okay so teach ya how to have fun

yeah

okay (1.5) that that's pretty appropriate (2.0)

S2 Roger um (2.2) to get a week off school

\section{Analysis}

In turn 16 Len introduces himself and puts forward his reasons as to why the school has year nine camp, 'teach us about the bush and have fun stuff'. The inclusion of 'the bush' possibly relates to Len's realisation that this has proven to be a successful reply used by another student who responded earlier. In turn 17 the leader can be observed using the 'okay so' utterance which serves to acknowledge the student's contribution prior to the issuing of a formulation of the student's response. The leader's formulation 'teach ya how to have fun', omits any reference to the bush and introduces the notion that the purpose of camp is to teach the boys how to have fun. The students 'doing' fun stuff is transformed into a possible pedagogical aim of camp; how to have fun is something that will be taught. The vagueness of the term 'stuff' is removed in the formulation. In turn 18 the leader's formulation is confirmed by the student with 'yeah'.

In turn 19 the leader uses the acknowledgement token 'okay' with a comment on the 'quality' of the response, 'that that's pretty appropriate'. It is possible that the considerable pause (1.5) after the issuing of 'okay' indicates a period of indecision on the part of the leader as to whether or not to pursue the interaction with this student further. This somewhat tentative and qualified evaluation is not frequently seen in the data where most of the leader's closing turns are marked by a one or two word acceptance/confirmatory statement.

\section{Discussion}

The use of a formulation allows the leader to articulate a preferred answer when an adequate reply has not been supplied by the student. By using a formulation the leader can address the student, and the group as the overhearing audience, for the instructional purposes of stating the 'real' and 'valued' understanding of this utterance in this setting. The student's response provides the foundation on which the leader can build a recognisable and contextually appropriate answer. As Edwards (1980) notes the 'decidability of the sufficiency' of the student reply lies with the leader. Should the leader deem the reply insufficient he is able to make additions or deletions as necessary to fulfil the criteria that he established in the opening turn when he established the topic. As was witnessed in transcript one he was also able to expand upon the student's reply to highlight a pedagogical point that he wished to stress.

In these two transcripts, and the larger corpus of data, there was an overwhelming preference for turn-closure to be signalled by a positive confirmation of the student 
contribution by the leader. This may, on first appearance, provide evidence of an environment where participants are commended for the content of their replies and encouraged to share their ideas. I argue that these closing confirmatory statements can be seen not so much as an indication of the acceptability of the initial student response but as a confirmation of the student's agreement with the leader's formulation. The students are 'praised' for accepting the leader's formulation of their response, which allows the closing of their turn at talk and movement towards the completion of the procedural requirements of the session. It is arguably the case that an immediate acceptance is more an indicator of the acceptability of the student response than a confirmatory utterance issued following a multi-turn exchange involving a leader formulation. To view a series of confirmatory utterances as markers of successful student contributions does not take into account the subtle interactional work involved in negotiating an acceptable response.

There is a certain ironic quality to these interactions. It is the leader's version of what the students have said that becomes confirmed as the accepted reason for being on camp or for having a successful day, rather than the students' versions. This form of verbal facilitation has the potential for becoming a platform from which the leader can articulate what it is that he desires as an outcome, a platform that is 'hidden' behind the apparent student-centeredness that is based on the apparent primacy of the students' contributions to the discussion.

The revoicing of the student reply allows the leader to not only articulate a preferred version but it also serves to create a 'model' answer for the other students. As a gloss on what is an acceptable reply, a formulation provides a resource for forthcoming student speakers to interpret and compare their understanding of what constitutes a valued contribution in this setting. By providing a formulation of an 'inadequate' student response the leader is not only providing a clarification and expansion for that particular student, he is also publishing an item that the other students can now be held accountable for having heard.
The participants' sequential interaction in these transcripts commences with a student response and concludes with a positive confirmation of the student's contribution. Within this sequence the leader exhibits 'superior' interactional rights through his unchallenged right to formulate the students' responses.

\section{Conclusion}

I have sought to demonstrate how formulations can be used in facilitation sessions to shape and constrain the options for future speakers and how they provide a powerful tool for the leader to confirm what is relevant for the students in this setting. I have argued that when the student is given the opportunity to comment on the leader's formulation of his initial response the predominant action will be a confirmation of the leader's 'take' on what he is claimed to have said. This preference for confirmations has important implications for understanding the prevalence of agreements and confirmatory utterances in facilitation sessions. For as Sacks (1987) notes, if a system "had a built-in bias for agreement, and you did not know about it, then you'd be counting a whole bunch of things as agreements that might well be accounted for in other ways" (p. 67). I have also briefly discussed how high-grade assessments (Antaki et al., 2000) such as 'great' and 'excellent' may function as 'markers' of the successful completion of a student's turn at talk rather than as evaluative comments on the content of the student reply.

Formulations provide the leader with a powerful means to shape the direction of the talk and to control what is admitted as valued knowledge. The employment of a formulation permits the leader to embark on more elaborate instructional work than is otherwise possible in the simple acceptance format where the evaluation is limited to a single utterance (e.g. 'yes'). This point is commented on by Heap (1985) who acknowledges that when a teacher does not offer an immediate acceptance of the student response, but instead issues a formulation of the student's reply, it provides the teacher with the opportunity to transmit knowledge to students. Heyman (1986) points out that formulations are also a familiar features of classroom discourse and that they are an important instructional 
device that assist the teacher to construct a corpus of knowledge for which the students will be accountable.

Formulations perform an important function in these facilitation sessions in that they avoid the potential problem of the leader having to issue a 'negative' evaluation of a student contribution. Throughout the data there is an absence of direct faulting of a student response by the leader, although he does on occasion ask the students to rearticulate or explain problematic replies. By formulating the student response into a more appropriate form the leader can articulate a 'correct' reply by building on the 'bare bones' of a student answer thus giving the appearance of valuing the student's contribution. In this way facilitation appears to become a positive experience for all parties.

The leader's use of formulations of answers is more common in the data than immediate leader acceptances of student responses. This may suggest a difference between what the students believe to have been learnt, as the result of reflection on experience, and the leader's version of what has been or should be learnt. The student's reply, which was purportedly based on his experience, has been formulated by the leader into an account that fulfils the criteria of appropriate 'leader sanctioned' knowledge. Thus the 'uniqueness' of the student's experience turns out to be a managed social accomplishment (Perakyla \& Silverman, 1991) that is located in the specific practices of facilitation.

So what does this mean for our practice as facilitators? I suggest that it calls into question some of the underlying assumptions about how we might use paraphrases in group discussions. As demonstrated paraphrases (formulations) of student responses can act as a means of articulating a leader sponsored version of events. In this sense the use of leader paraphrases has the potential to act as a means of direct instruction rather than an opportunity for students to genuinely share their reflections on experiences they have had.

My call for educators to critical reflect on current practice finds support in the writings of Boud (1997) and Hovelynck (1999). Boud (1997) offers a caution as to whether or not reflection can act as a catalyst for change, "I say can be rather than is because there is evidence of poor educational practice on the part of those who endeavour to prompt reflection" ( $p$. 1). While I am drawing attention to the role that paraphrasing can have as a means of direct instruction, a similar theme, with reference to leader influence, has been expounded by Hovelynck (1999). He has written on the potential for leader selected metaphors to frame student experience and he cautions against the imposition of leader defined metaphors for interpreting experiences as this may prevent students from developing their own metaphors that reflect their experience.

The issue that faces us is to critically evaluate our own practice to ensure that we employ practices that "facilitate forms of learning in which the participants remain the 'agents' of their experience and their learning" (Hovelynck, 1999, p. 22). By making the consequences of our actions more transparent, in this case how paraphrases/summaries may act as vehicles to privilege our understandings and versions of events, we may have cause to explore new ways for students to meaningful reflect on their experiences; ways which are less directive than is presently the case in some verbal facilitation sessions. Thus, while the desirability of facilitation of experiences through reflection and discussion is widely accepted in both experiential and adventure education literature, the implementation of the theory is becoming increasingly contested terrain.

\section{References}

Antaki, C., Houtkoop-Stennstra, H., \& Rapley, M. (2000). "Brilliant. Next question...": High-grade assessment sequences in the completion of interactional units. Research on Language and Social Interaction, 33(3), 235-262.

Baker, C. (1997). Ethnomethodological studies of talk in educational settings. In D. Corson (Ed.), Encyclopedia of language and education (Vol. 3 Oral discourse and education, pp. 43-52). 
Dordrecht, Netherlands: Kluwer Academic Publishers.

Baker, C. D. (1991). Literacy practices and social relations in classroom reading events. In A. Luke (Ed.), Towards a critical sociology of reading pedagogy (pp. 161-188). Amsterdam: John Benjamins.

Bell, M. (1993). What constitutes experience? Rethinking theoretical assumptions. Journal of Experiential Education, 16(1), 19-24.

Boud, D. (1997). Reflection as a catalyst for change. Paper presented at the Tenth National Outdoor Education Conference, Sydney, Australia.

Boud, D., Keogh, R., \& Walker, D. (1985). Promoting reflection in learning: a model. In D. Walker (Ed.), Reflection: Turning experience into learning (pp. 18-40). London: Kogan Page.

Bowles, S. (1996). Techniques and philosophy. The Journal of Adventure Education and Outdoor Leadership, 13(2), 7-19.

Brackenreg, M., Luckner, J. L., \& Pinch, K. (1994). Essential skills for processing adventure experiences. Journal of Experiential Education, 17(3), 45-47.

Brown, M. (2002a). The facilitator as gatekeeper: A critical analysis of social order in facilitation sessions. Journal of Adventure Education and Outdoor Learning, 2(2), 101-112.

Brown, M. (2002b). Interaction and social order in adventure education facilitation sessions. Unpublished doctoral dissertation, University of Queensland, Brisbane.

Chapman, S. (1995). What is the question? In K. Warren, M. Sakofs \& J. S. Hunt, Jr. (Eds.), The theory of experiential education (3 ed., pp. 236-239). Dubuque, IA: Kendall/Hunt.

Dickson, T. J. (1996). Processing the experience-broadening the vision. Australian Journal of Outdoor Education, 2(2), 11-16.

Drew, P., \& Heritage, J. (1992). Talk at work: Interaction in institutional settings. Cambridge, UK: Cambridge University Press.

Edwards, A. D. (1980). Patterns of power and authority in classroom talk. In $P$. Woods (Ed.), Teacher strategies: Explorations in the sociology of the school (pp. 237-253). London: Croom Helm.

Estes, C. A., \& Tomb, S. (1995). Is cheese food really food? a.k.a. Some conscious alternatives to overprocessing experience. Paper presented at the 1995 International Conference on Outdoor Recreation and Education (ERIC Document Reproduction Service No. ED 404 080).

Garfinkel, H., \& Sacks, H. (1970). On formal structures of practical actions. In E. A. Tiryakian (Ed.), Theoretical sociology: Perspectives and developments (pp. 337366). New York: Appleton Century Crofts.

Gass, M. A. (1990). Transfer of learning in adventure education. In J.C. Miles \& S. Priest (Eds.), Adventure education (pp. 199-208). State College, PA: Venture Publishing.

Heap, J. L. (1985). Discourse in the production of classroom knowledge: Reading lessons. Curriculum Inquiry, 15, 245-279.

Heap, J. L. (1997). Conversation analysis methods in researching language and education. In D. Corson (Ed.), Encyclopedia of language and education (Vol. 8 Research methods in language and education, pp. 217-225). Dordrecht, Netherlands: Kluwer Academic Publishers.

Heritage, J. C., \& Watson, D. R. (1979). Formulations as conversational objects. In G. Psathas (Ed.), Everyday language studies in ethnomethodology (pp. 123162). New York: Irvington.

Heritage, J. C., \& Watson, D. R. (1980). Aspects of the properties of formulations in natural conversations: Some instances analysed. Semiotica, 30(3/4), 245-262.

Heyman, R. D. (1986). Formulating topic in the classroom. Discourse Processes, 9, 37-55.

Hovelynck, J. (1999). Facilitating the development of generative metaphors: Re-emphasizing participants' guiding images. Australian Journal of Outdoor Education, 4(1), 12-24.

Joplin, L. (1995). On defining experiential education. In K. Warren, M. Sakofs \& J. Hunt, Jr. (Eds.), The theory of experiential education (3 ed., pp. 15-22). Dubuque, IA: Kendall/Hunt.

Knapp, C. E. (1990). Processing the adventure experience. In J. C. Miles \& S. Priest (Eds.), Adventure education (pp. 
189-198). State College, PA: Venture Publishing.

Kolb, D. A. (1984). Experiential learning. Englewood Cliffs, NJ: Prentice-Hall.

Luckner, J. L., \& Nadler, R. S. (1997). Processing the experience: Strategies to enhance and generalize learning (2nd ed.). Dubuque, IA: Kendall Hunt.

Maynard, D. W., \& Clayman, S. E. (1991). The diversity of ethnomethodology. Annual Review of Sociology, 17, 385418.

Perakyla, A., \& Silverman, D. (1991). Owning experience: Describing the experience of other persons. Text, 11(3), 441-480.

Priest, S., \& Gass, M. A. (1997). Effective Leadership in Adventure Programming. Champaign, IL: Human Kinetics.

Priest, S., Gass, M. A., \& Gillis, L. (2000). The essential elements of facilitation. Dubuque, IA: Kendall/Hunt.

Priest, S., \& Naismith, M. (1993). A model for debriefing experiences. Journal of Adventure Education and Outdoor Leadership, 10(3), 20-22.

Proudman, B. (1995). Experiential education as emotionally engaged learning. In $\mathrm{K}$. Warren, M. Sakofs \& J. S. Hunt, Jr. (Eds.), The theory of experiential education (3 ed., pp. 240-247). Dubuque, IA: Kendall/Hunt.

Quinsland, L. K., \& Van Ginkel, A. (1984). How to process experience. Journal of Experiential Education, 7(2), 8-13.
Sacks, H. (1987). On the preferences for agreement and contiguity in sequences in conversation. In J. R. E. Lee (Ed.), Talk and social organisation (pp. 54-69). Clevedon Philadelphia: Multilingual Matters.

Smith, C. (1996). From disagreement to agreement: A conversation analytic perspective on mediation. Unpublished doctoral dissertation, The University of Queensland, Brisbane.

Spegel, N. (1996). Lawyers learning to survive: The application of adventurebased learning to skills development. Journal of Professional Legal Education, 14(1), 25-50.

Sugarman, D. A., Doherty, K. L., Garvey, D. E., \& Gass, M. A. (2000). Reflective learning: Theory and practice. Dubuque, IA: Kendall/Hunt.

\section{About the Author}

Mike Brown, PhD. is a lecturer in the Sport and Outdoor Recreation program at the Faculty of Education, Monash University.

Email:

mike.brown@education.monash.edu.au

\section{Acknowledgements}

This research was conducted with the support of the School of Education, University of Queensland. My thanks to the reviewers for their comments on an earlier draft of this paper. 